\title{
Comparative insilico Docking Analysis of Curcumin and Resveratrol on Breast Cancer Proteins and their Synergistic Effect on MCF-7 Cell Line
}

\author{
Rathinasabapathy Pushpalatha*, Subramanian Selvamuthukumar, Duraisamy Kilimozhi \\ Department of Pharmacy, Annamalai University, Annamalai Nagar-608002, Tamil Nadu, INDIA.
}

\begin{abstract}
Object: To compare the molecular activity of curcumin and resveratrol on selected breast cancer protein receptors and to investigate their combination for synergism against human breast cancer MCF-7 cell line. Method: Curcumin and resveratrol were subjected to insilico docking studies using glide to investigate the drug activity against HER2, human oestrogen receptor, ERBB2, epidermal growth factor tyrosine protein kinase C-SRC, and HSP9O proteins. MTT assay was used to assess cell viability of curcumin and resveratrol individually and in combination at 1:1,1:3 and $3: 1$ ratio respectively. Results: The insilico study revealed good glide score and glide energy for these drugs against breast cancer protein. Curcumin and resveratrol has more binding affinity for proteins with varying amino acid interaction sites. $I C_{50}$ for curcumin and resveratrol was observed to be 21.29 and $38.30 \mu \mathrm{g} / \mathrm{ml}$ respectively. $I C_{50}$ for the combined treatment with curcumin and resveratrol at the ratio of 1:1,1:3 and 3:1 were observed to be $28.06,15.20$ and $8.29 \mu \mathrm{g} / \mathrm{ml}$ respectively. Combined treatment of curcumin and resveratrol at equal ratio exhibited additive effects while at the ratio of $1: 3$ and 3:1 exhibited a strong synergistic effect on the
\end{abstract}

cytotoxicity of MCF-7 cell line. Conclusion: Insilico docking analysis helped in identifying and organizing the structural similarity/diversity at the molecular level activity of curcumin and resveratrol. In vitro cell line study provides an insight into the potential application of curcumin and resveratrol codelivery for the chemoprevention and treatment of breast cancer.

Key words: Combinatorial effect, Curcumin, Resveratrol, Human breast cancer MCF -7 cells, Insilico anticancer screening, Synergism.

Key Message: Synergistic effect of curcumin and resveratrol on breast cancer observed.

Correspondence :

R Pushpalatha, Research Scholar, Department of Pharmacy, Annamalai University, Annamalai Nagar-608002 Tamil Nadu, INDIA.

Email: rkpushpa@gmail.com

DOI: 10.5530/jyp.2017.9.94

\section{INTRODUCTION}

Cancer is a disease with abnormal cell growth and uncontrolled multiplication of the cells within the body. Cancer therapy is currently modelled by surgery, radiotherapy and chemotherapy. Most cancers are treated with chemotherapy. Drugs from herbal sources are less toxic, less expensive and easily available. Curcumin is a polyphenol obtained from Curcuma longa plant. It is nontoxic and reported for analgesic, anti-inflammatory, and anti-oxidant activity. ${ }^{1}$ It is a potent anticancer agent with various mechanisms, including inhibition of proliferation of cancer cells, transformation of normal cells, inhibit the synthesis of protein responsible for tumor growth, etc. Resveratrol is a natural drug found in red wine and grape skins possessing high antioxidant property and promising candidate for antimicrobial, anti-inflammatory and anticancer activity. ${ }^{2}$

Recent research focus on multidrug combinations in cancer chemotherapy in which one drug enhances the activity of the other, by varying mechanism. Natural drugs curcumin and resveratrol exhibit close similarities in molecular structures and shares the absorption and efflux between them replacing one for the other when used in combination. ${ }^{3}$ These drugs exhibit a synergistic anticancer effect in colon cancer, lung cancer and hepatocellular carcinoma ${ }^{4-6}$ They found to exert synergism against inflammation. ${ }^{7}$ The Synergistic potential of curcumin and resveratrol in declining the active tumour suppressor protein in the lungs of Benzo[a]pyrene treated mice were reported earlier. ${ }^{8}$ In vitro cell line study and in vivo study in mice for prostatic adenocarcinoma using curcumin and resveratrol drug combination induced apoptosis and decreased cell growth. ${ }^{9}$ Enhancement of curcumin activity in the pres- ence of resveratrol is reported against head and neck carcinoma. ${ }^{10}$ The synergism mechanism was earlier reported for antioxidant activity where if curcumin is oxidised, resveratrol regenerates curcumin by reducing it and enhance the antioxidant activity of curcumin. ${ }^{11}$ Only few studies are reported for combined use of curcumin and resveratrol for breast cancer. Combination of these drugs resulted in apoptosis in cigarate smoke condensate transformed breast cancer epithelial cells. ${ }^{12}$ This article aims to compare the molecular activity of curcumin and resveratrol on certain breast cancer receptors, as an in vitro study to explore the combined use of curcumin, resveratrol in breast cancer treatment.

Curcumin was reported to downregulate human epidermal growth factor(HER2) oncoprotein overexpressed in $20-30 \%$ of breast cancers. ${ }^{13}$ It inhibits the expression of ER downstream genes and exhibits oestrogen dependent antiproliferation. ${ }^{14}$ Activity of ERK1/K2 MAP kinase is down regulated by curcumin in a dose dependent manner in breast cancer cells expressing ERBB2. ${ }^{15}$ It is a potent and selective inhibitor of phosphorylase Kinase including tyrosine kinase C-SRC. ${ }^{16}$ Resveratrol inhibits PI3K/ AKT pathway responsible for the oncogenic driver in breast cancer. ${ }^{17} \mathrm{It}$ causes cell death by altering the progression of cell cycle through fatty acid synthase inhibition in breast cancer with HER2 positive. Resveratrol acts as an antioestrogen to reduce migration and invasion of cancer cells. ${ }^{18}$ Resveratrol is reported to down regulate the activity of MAPK pathways by inhibiting protein tyrosine kinases. ${ }^{19}$ 
Based on the mechanisms of curcumin and resveratrol against cancer cells, breast cancer protein HER2, human oestrogen receptor, epidermal growth factor tyrosine kinase receptor ERBB2, tyrosine protein kinase C-SRC and HSP90 were selected to study the molecular activity and compare the binding interaction of curcumin and resveratrol. Among the various computational methods employed to assess the anticancer potential of drugs, docking is the most widely used tool. ${ }^{20}$ Hence insilico molecular docking analysis were performed on the selected cancer receptors for curcumin and resveratrol. With the interaction study results against these proteins, inhibition of cell growth by curcumin, resveratrol individually and in combination against MCF-7 cells were examined to study the synergistic effect on cytotoxicity.

\section{MATERIALS AND METHODS}

\section{Molecular Docking Analysis}

\section{Preparation of Protein Structure}

The protein data bank (PDB) web contains a collection of 3D structure of large biological molecules including proteins and nucleic acids. The structure of HER2, Human Oestrogen receptor, ERBB2 receptor tyrosine kinase, Tyrosine protein kinase C-SRC and HSP90 proteins having PDB ID $4 \mathrm{RJ} 3,2 \mathrm{IOK}, 2 \mathrm{~A} 91,2 \mathrm{SRC}$ and 2VCJ with resolution of $1.63 \mathrm{~A}^{\circ}, 2.4 \mathrm{~A}^{\circ}$, $2.5 \mathrm{~A}^{\circ}, 1.5 \mathrm{~A}^{\circ}$ and $2.5 \mathrm{~A}^{\circ}$ respectively was retrieved from the protein data bank http://www.rcsb.org/pdb/. All the interacting heavy atoms, water molecules, metal ions are removed and added with hydrogen atoms, stabilized with minimized energy using "protein preparation wizard" of Schrodinger Maestro. The modelled structures of proteins were validated through Ramachandran plot using PROCHECK.

\section{Ligand Preparation}

Drug compounds curcumin and resveratrol were obtained from the PubChem website https://pubchem.ncbi.nlm.nih.gov/ as SDF format and then converted and optimized to ligands using "ligprep" of Schrodinger Maestro version 10.6.014.

\section{Docking}

The compounds prepared as ligands were docked against each of the prepared protein receptors using "ligand docking" of Schrodinger Maestro. Docking analysis was performed at extra precision mode with ligands made flexible. The interactions were calculated using the glide score, which was generated by the best fit of the ligand and the receptor. The ligands docked using GLIDE-Version 7.1 was graded with glide score and glide energy. The docking result for each ligand screened against each receptor protein were recorded.

\section{Cell Line Study}

\section{Chemicals and reagents}

Curcumin was purchased from Hi Media and resveratrol was obtained as a gift sample from Sami Labs limited, Bangalore. Other chemicals used were of analytical grade.

\section{Cell culture}

Human breast MCF-7 cells were obtained from National centre for cell sciences, Pune, India. Cells were maintained in Dulbecco's Modified Eagle's Medium (DMEM) containing 10\%(v/v) fetal bovine serum (FBS) and incubated at $37^{\circ} \mathrm{C}$ of $5 \% \mathrm{CO}_{2}$.

\section{Test sample}

Sample containing curcumin, resveratrol, curcumin and resveratrol at the ratio of 1:1 1:3, 3:1 by mass were used for the study. Stock solution of $1 \mathrm{mg} / \mathrm{ml}$ was prepared for each sample. $500 \mu \mathrm{l}$ of each stock solution was then serial diluted to obtain different concentration ranging from $250 \mu \mathrm{g} / \mathrm{ml}$ to $3.906 \mu \mathrm{g} / \mathrm{ml}$.

\section{Cell viability}

Cell viability was measured using MTT (3-(4,5 dimethyl thazole-2yl)-2,5diphenyl tetrazolium bromide) method. ${ }^{21}$ The cell count was adjusted to $1.0 \times 10^{5}$ cells $/ \mathrm{ml}$ using DMEM medium containing $10 \%$ FBS. $100 \mu$ of the diluted cell suspension (approximately 10,000 cells/well) was added to each well of a 96 well microtiter plate. After $24 \mathrm{~h}$, the supernatant was removed and the monolayer was washed with medium. $100 \mu \mathrm{l}$ of samples of different concentrations prepared in the media were added. The plates were incubated for $72 \mathrm{~h}$ at $37^{\circ} \mathrm{C}$ in $5 \% \mathrm{CO}_{2}$ atmosphere. After $72 \mathrm{~h}$, the sample solutions in the wells were discarded and $20 \mu \mathrm{l}$ of MTT $(2 \mathrm{mg} / \mathrm{ml})$ in MEM-PR (MEM without phenol red) was added to each well.

The plates were gently shaken and incubated for $3 \mathrm{~h}$ at $37^{\circ} \mathrm{C}$ in $5 \% \mathrm{CO}_{2}$ atmosphere. The supernatant was removed. Then $50 \mu$ lof isopropanol was added and the plates were gently shaken to solubilize the formed formazan. The absorbance was measured using a micro plate reader at a wavelength of $540 \mathrm{~nm}$. Cell viability is calculated as follows

$$
\text { Cell viability }(\%)=\frac{\text { Mean OD }}{\text { Control OD }} \times 100
$$

Concentration of different test samples required to inhibit cell growth by $50 \%$ values was generated from the dose-response curves for each cell line. The data were analysed by CompuSyn software to compute the combination index (CI) values, where the $\mathrm{CI}$ value $<1,=1$, and $>1$ refer to synergetic, additive, and antagonistic effects, respectively. ${ }^{22}$

\section{Statistical Analysis}

All the statistical analysis was carried out by GraphPad Prism 7.0. All the data were expressed as mean $\pm S D$ of three independent experiments. One-way ANOVA was used to analyse all experimental data. Statistical significance was accepted at the level of $\mathrm{p}<0.05$.

\section{RESULTS}

\section{Molecular Docking Analysis}

The docking results of curcumin and resveratrol with different breast cancer proteins are shown in Table 1. The glide score of curcumin with breast cancer proteins HER2, oestrogen receptor, ERBB2, tyrosine kinase and HSP90 are $-12.1,-9.92,-8.30,-8.22$ and $-8.05 \mathrm{kcal} / \mathrm{mol}$ respectively, and the glide energy being $-56.46,-47.85,-43.21,-47.36$ and $-52.63 \mathrm{kcal} /$ mol respectively. The glide score of resveratrol with breast cancer proteins HER2, oestrogen receptor, ERBB2, tyrosine kinase and protein HSP90 are $-7.56,-8.81,-6.37,-5.99$ and $-6.47 \mathrm{kcal} / \mathrm{mol}$ respectively, and the glide energy being $-36.39,-36.23,-33.18,-31.74$ and $-39.77 \mathrm{kcal} / \mathrm{mol}$ respectively.

Figures 1 to 5 represents the interaction of the ligands with the active amino acid sites of different cancer protein receptor illustrated as $2 \mathrm{D}$ (section $\mathrm{A}$ and $\mathrm{C}$ ) and $\mathrm{DD}$ (section $\mathrm{B}$ and $\mathrm{D}$ ) pictures. Amino acids GLU 1419, THR 1347 of the oestrogen receptor interacts with curcumin whereas amino acids GLY 1521, LEU 1387 and LEU 1346 interacts with resveratrol (Figure 2). Similarly, with tyrosine protein kinase C-SRC docking analysis resulted in interaction of amino acids ARG 388 with curcumin whereas amino acids GLN 275, GLU 339 and MET 341 interacts with resveratrol (Figure 4). Interaction of curcumin and resveratrol with HER2, ERBB2 and HSB90 protein have common amino acid binding sites LEU83, THR 2 and GLY 97 respectively. (Figure 1,3 and 5). Table 2 represents the different amino acid binding sites of curcumin and resveratrol in each cancer protein receptor. 

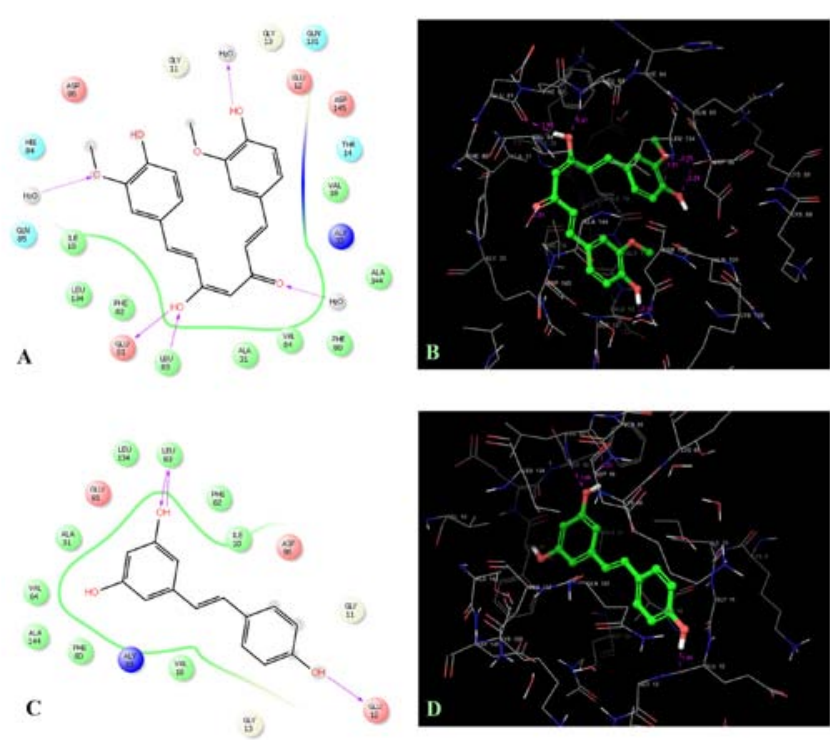

Figure 1: 2D and 3D interaction of curcumin and resveratrol against breast cancer protein HER2(PDB ID 4RJ3).
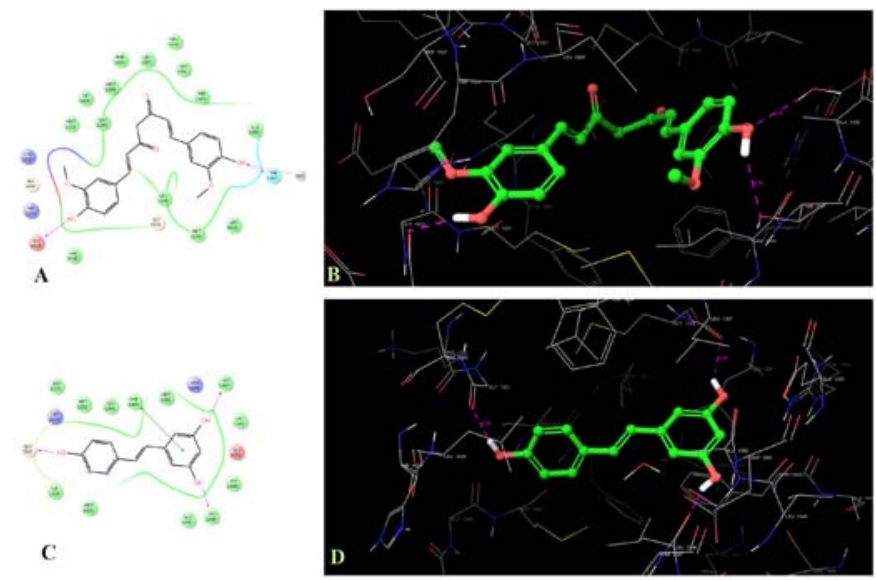

Figure 2: 2D and 3D interaction of curcumin and resveratrol against Human oestrogen receptor responsible for breast cancer (PDB ID 2IOK).

\section{MTT assay (MCF-7 cell line)}

The results of MTT assay for cytotoxicity against MCF-7 cell line are presented in Figure 6A and 6B. Percentage cell viability exhibited by treatment with different drug combination ratio was found to be statistically low at the concentration ratio of $7.81,15.21$ and $31.25 \mu \mathrm{g} / \mathrm{ml}$ when compared against curcumin and resveratrol treatment alone $(1 \mathrm{a}-\mathrm{P}<0.05$, $1 \mathrm{~b}-\mathrm{P}<0.01$ against curcumin and $2 \mathrm{a}-\mathrm{P}<0.05, \quad 2 \mathrm{~b}-\mathrm{P}<0.01,2 \mathrm{c}-\mathrm{P}<0.001$ against resveratrol). Table 3 represents the $\mathrm{IC}_{50}$ values of curcumin, resveratrol and different combination ratio against MCF-7 cell line along with CI and interpretation for synergism. ${ }^{23} \mathrm{IC}_{50}$ value observed for curcumin is $21.29 \mu \mathrm{g} / \mathrm{ml}$ and for resveratrol is $38.30 \mu \mathrm{g} / \mathrm{ml}$ for resveratrol. Figure $6 \mathrm{C} . \mathrm{IC}_{50}$ values for different ratio of combined treatment of drugs was found to be $28.06 \mu \mathrm{g} / \mathrm{ml}$ (1:1 ratio), $15.20 \mu \mathrm{g} / \mathrm{ml}$ (1:3 ratio) and $8.29 \mu \mathrm{g} / \mathrm{ml}(3: 1)$. The combination index (CI) for different combination ratio is illustrated in Figure 6D. CI value of 1.08 was observed for

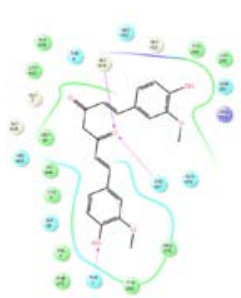

A
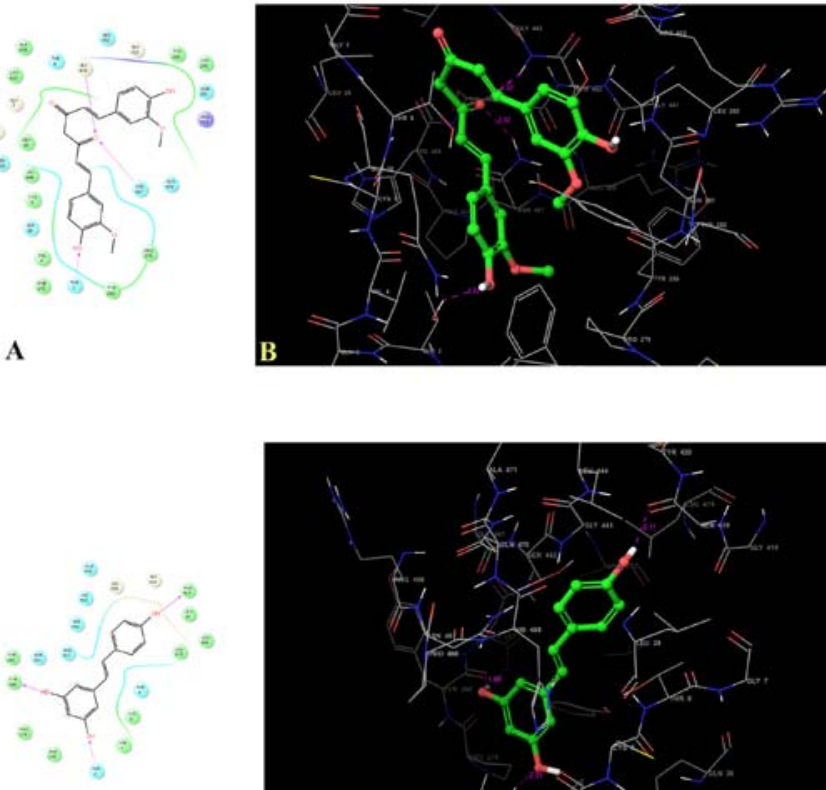

C

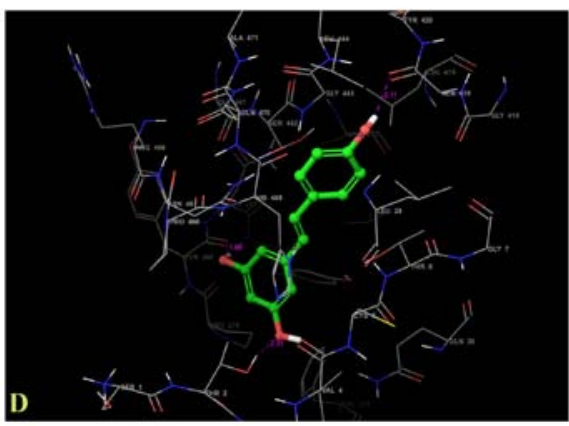

Figure 3: $2 \mathrm{D}$ and 3D interaction of curcumin and resveratrol against breast cancer protein ERBB2 receptor tyrosine kinase (PDB ID 2A91).
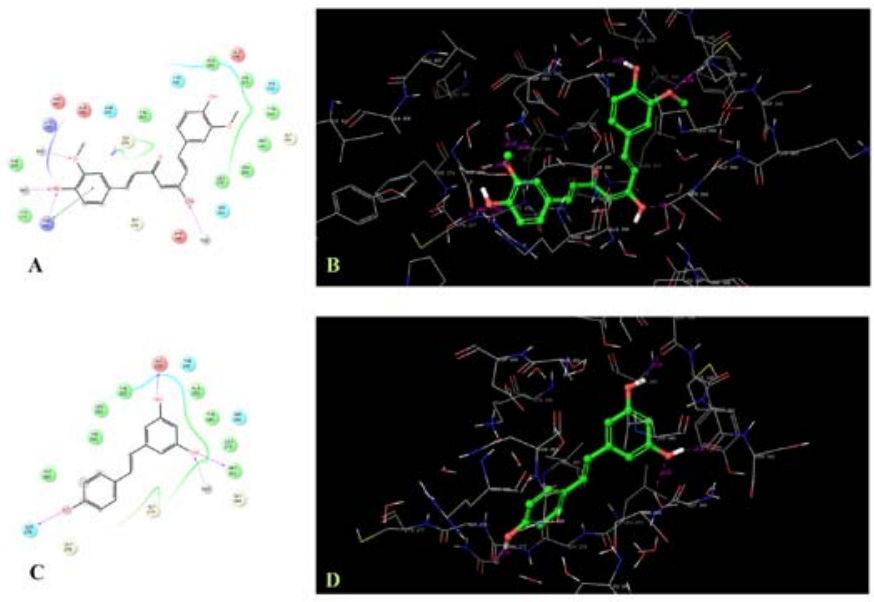

Figure 4: 2D and 3D interaction of curcumin and resveratrol against Tyrosine protein kinase C-SRC (PDB ID 2SRC).

1:1 combination ratio indicating additive effect. CI values obtained for 1:3 and 3:1 drug combination ratio was observed to be 0.382 and 0.341 respectively, indicating synergistic effect.

\section{DISCUSSION}

A higher negative value of glide score and glide energy indicate more binding affinity. The hydrogen bond score indicates atomic coordinates (type and geometry of bonding) and Van der Waals interactions. The more negative hydrogen bond scale, the stronger is the hydrogen bonding and hence greater is the interaction of ligand with the protein receptor. The negative values ranging from -8.05 to -12.1 glide score and glide energy ranging from -43.21 to -56.46 for curcumin with strong hydrogen bonding and more lipophilicity indicates better interaction with the 


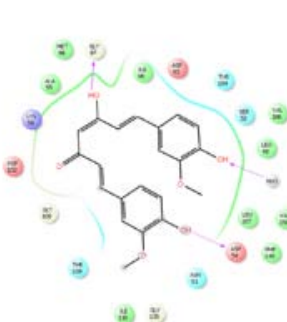

A
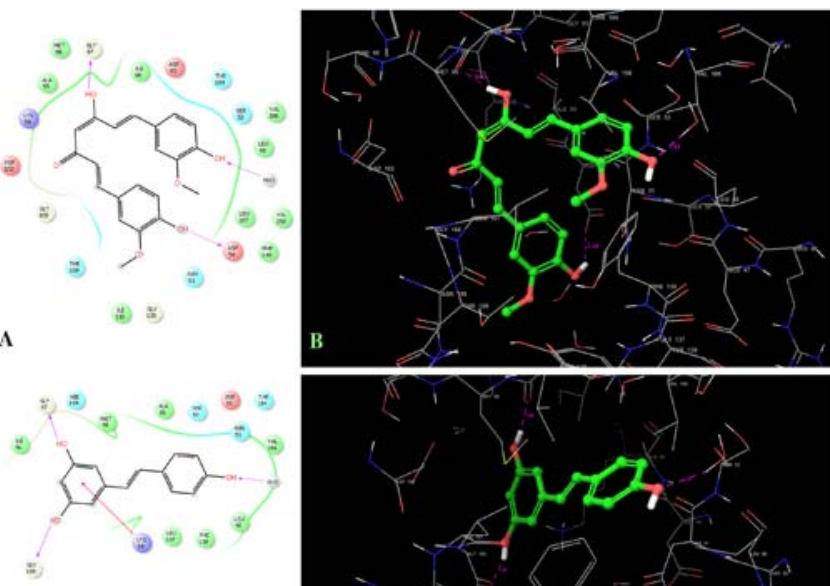

Figure 5: 2D and 3D interaction of curcumin and resveratrol against HSB90 (PDB ID 2VJC).

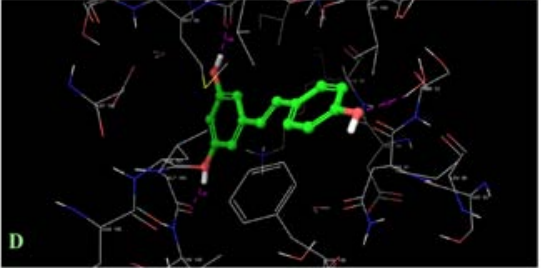

active sites of cancer proteins and inactivating them. Similarly, the negative values ranging from -5.99 to -8.81 glide score and glide energy ranging from -31.74 to -39.77 for resveratrol indicates better interaction with cancer proteins, thus inactivating them and inhibiting their contribution to cancer progression. The amino acid sites with which curcumin interacted is different from the amino acid sites interacted by resveratrol with human oestrogen receptor and tyrosine protein kinase C-SRC proteins. The protein binding of curcumin and resveratrol at different sites might help in synergistic activity to inhibit cancer progression. Hence, in vitro cytotoxicity study against MCF-7 human breast cancer cells were performed to investigate the synergistic activity of curcumin and resveratrol.

MTT assay resulted in cell cytotoxicity in a concentration dependent manner for curcumin and resveratrol. Combined treatment of curcumin and resveratrol significantly increased the cytotoxicity effect on human breast cancer cells $(\mathrm{P}<0.05)$ when compared with the either drugs alone. Combined treatment of curcumin with resveratrol at 1:1 decreased the IC $_{50}$ value to $28.06 \mu \mathrm{g} / \mathrm{ml}$ comparatively with resveratrol $(38.30 \mu \mathrm{g} / \mathrm{ml})$ but increased comparatively with curcumin alone treatment $(21.29 \mu \mathrm{g} / \mathrm{ml})$. Alternatively, treatment with 1:3 and 3:1 combination ratio enhanced the growth inhibition significantly as indicated by markedly decreased value

Table 1: Results of Docking analysis of curcumin and resveratrol against different cancer proteins.

\begin{tabular}{ccccccccccc}
\hline \multirow{2}{*}{$\begin{array}{c}\text { Docking } \\
\text { parameters }\end{array}$} & \multicolumn{2}{c}{ PDBID 4RJ3 } & \multicolumn{2}{c}{ PDBID 2IOK } & \multicolumn{2}{c}{ PDBID 2A91 } & \multicolumn{2}{c}{ PDBID 2SRC } & \multicolumn{2}{c}{ PDBID 2VCJ } \\
\cline { 2 - 11 } & CUR & RES & CUR & RES & CUR & RES & CUR & RES & CUR & RES \\
\hline Glide Score & -12.1 & -7.56 & -9.92 & -8.81 & -8.30 & -6.37 & -8.22 & -5.99 & -8.05 & -6.47 \\
Glide Energy & -56.46 & -36.29 & -47.85 & -36.23 & -43.21 & -33.18 & -47.36 & -31.74 & -52.63 & -39.77 \\
Hbond & -4.17 & -1.51 & -2.05 & -1.59 & -1.82 & -1.57 & -4.03 & -1.64 & -1.91 & -1.89 \\
LipophilicEVDw & -4.9 & -3.7 & -5.8 & -4.6 & -5.8 & -4.2 & -3.4 & -3.6 & -5.7 & -3.6 \\
\hline
\end{tabular}

CUR-curcumin, RES-resveratrol

Table 2: Amino acids binding sites of curcumin and resveratrol in different cancer proteins.

\begin{tabular}{cccccc}
\hline \multirow{2}{*}{ Drugs } & PDBID 4RJ3 & PDBID 2IOK & PDBID 2A91 & PDBID 2SRC & $\begin{array}{c}\text { PDBID } \\
\text { 2VCJ }\end{array}$ \\
\cline { 2 - 6 } & HER2 & $\begin{array}{c}\text { Human Oestrogen } \\
\text { Receptor }\end{array}$ & ERBB2 & $\begin{array}{c}\text { Epidermal growth } \\
\text { factor tyrosine } \\
\text { protein kinase }\end{array}$ & HSB90 \\
\hline \multirow{2}{*}{ Curcumin } & LEU 83 & GLU 1419 & GLY 443 & ARG 388 & GLY 97 \\
& GLU 81 & THR 1347 & THR 2 & ASP 54 \\
Resveratrol & LEU 83 & GLY 1521 & THR 2 & GLN 275 & GLY 97 \\
& LEU 1387 & TYR 280 & GLU 339 & GLY 108 \\
& LEU 1346 & ALA 419 & MET 341 & LYS 58 \\
\hline
\end{tabular}

Table 3: IC $\mathrm{C}_{50}$ of curcumin, resveratrol and their combination with Combination Index.

\begin{tabular}{cccc}
\hline Drug(s) & $\mathrm{IC}_{50}(\mu \mathrm{g} / \mathrm{ml})$ & $\mathrm{Cl}(\mathrm{Fa}=0.5)$ & Interpretation \\
\hline Curcumin & 21.29 & & \\
Resveratrol & 38.30 & 1.087 & Additive effect \\
CUR:RES (1:1) & 28.06 & 0.382 & Strong synergism \\
CUR:RES (1:3) & 15.21 & 0.341 & Strong synergism \\
\hline
\end{tabular}

Interpretation of results: CI >.3 antagonism; CI 1.1-1.3 moderate antagonism; CI 0.9-1.1 additive effect; CI 0.8-0.9 slight synergism; CI 0.6-0.8 moderate synergism; CI 0.4-0.6 synergism; CI 0.2-0.4 strong synergism 



Figure 6: $[6 \mathrm{~A}]$ Cell viability by MTT assay. Values represent the mean $\pm S . D(n=3) .1 \mathrm{a} P<0.05,1 \mathrm{~b} P<0.01$ represents the data compared with curcumin; 2 a $P<0.05$, $2 \mathrm{~b} P<0.01,2 \mathrm{C}<0.001$ represents the data compared with resveratrol. [6B] In vitro cytotoxicity plots of free curcumin, free resveratrol and their combination at different ratio after $72 \mathrm{~h}$ of treatment. [6C] IC $\mathrm{C}_{50}$ value of free curcumin, free resveratrol and their combination at different ratio. [6D] Combination Index analysis of curcumin and resveratrol combination at the ratio 1:1,1:3, 3:1.

of $\mathrm{IC}_{50}$ to $15.20 \mu \mathrm{g} / \mathrm{ml}$ and $8.29 \mu \mathrm{g} / \mathrm{ml}$ respectively. The CI analysis results suggest that the growth inhibitory effect of these two drugs was additive at $1: 1$ ratio $(\mathrm{CI}=1.08)$, while strongly synergistic at $1: 3$ and $3: 1$ ratio with CI value of 0.382 and 0.341 respectively.

\section{CONCLUSION}

Comparative molecular docking analysis of curcumin and resveratrol against various breast cancer protein receptors helped to explore their drug combination for breast anticancer activity. More negative glide score and energy results indicate more binding for breast cancer proteins by these drugs with varying amino acid interaction sites. Results of cell line study have shown that the combination of curcumin with resveratrol additively or synergistically increase the anticancer activity of either drug. Synergistic effect of drug combination against MCF-7 cells indicates that this drug combination could be a promising approach for breast cancer treatment and chemoprevention. To gain more confirmation in vivo studies must be further investigated. However the common problem with both the drugs is their poor solubility and low absorption resulting in poor bioavailability. ${ }^{24,25}$ Among the various techniques reported to overcome these limitations, Nano delivery is a promising approach. ${ }^{26-29}$
Delivering drug combination chemotherapeutics in nanocarrier base proves promising in advanced therapeutic approach on cancer cells by the enhanced pharmacokinetics of drugs, reduced drug-drug interaction and tailored drug release. ${ }^{30}$ Studies on combination drug delivery of curcumin and resveratrol using cyclodextrin based nanocarrier are in progress.

\section{REFERENCES}

1. Wilken R, Veena MS, Wang MB, Srivatsan ES. Curcumin: A review of anti-cancer properties and therapeutic activity in head and neck squamous cell carcinoma. Molecular cancer. 2011;10(1):12

2. Aluyen JK, Ton QN, Tran T, Yang AE, Gottlieb HB, Bellanger RA. Resveratrol: potential as anticancer agent. Journal of dietary supplements. 2012;9(1):45-56

3. Shindikar A, Singh A, Nobre M, Kirolikar S. Curcumin and Resveratrol as Promising Natural Remedies with Nanomedicine Approach for the Effective Treatment of Triple Negative Breast Cancer. Journal of Oncology. 2016;2016.

4. Du Q, Hu B, An HM, Shen KP, Xu L, Deng S, et al. Synergistic anticancer effects of curcumin and resveratrol in Hepa1-6 hepatocellular carcinoma cells. Oncology reports. 2013;29(5):1851-8.

5. Majumdar AP, Banerjee S, Nautiyal J, Patel BB, Patel V, Du J, et al. Curcumin synergizes with resveratrol to inhibit colon cancer. Nutrition and cancer. 2009;61(4):544-53.

6. Malhotra A, Nair P, Dhawan DK. Study to evaluate molecular mechanics behind 
synergistic chemo-preventive effects of curcumin and resveratrol during lung carcinogenesis. Plo S one. 2014;9(4):e93820

7. Csaki C, Mobasheri A, Shakibaei M. Synergistic chondroprotective effects of curcumin and resveratrol in human articular chondrocytes: inhibition of IL-1 $\beta$ induced NF-KB-mediated inflammation and apoptosis. Arthritis research and therapy. 2009;11(6):R165.

8. Malhotra A, Nair P, Dhawan D. Curcumin and resveratrol in combination modulates benzo (a) pyrene-induced genotoxicity during lung carcinogenesis. Human and experimental toxicology. 2012;31(12):1199-206.

9. Narayanan NK, Nargi D, Randolph C, Narayanan BA. Liposome encapsulation of curcumin and resveratrol in combination reduces prostate cancer incidence in PTEN knockout mice. International Journal of Cancer. 2009;125(1):1-8.

10. Masuelli L, Di-Stefano E, Fantini M, Mattera R, Benvenuto M, Marzocchella L, et al. Resveratrol potentiates the in vitro and in vivo anti-tumoral effects of curcumin in head and neck carcinomas. gene expression. 2014;4:5.(2014;5(21):10745)

11. Aftab N, Vieira A. Antioxidant activities of curcumin and combinations of this curcuminoid with other phytochemicals. Phyto therapy Research. 2010;24(4): 500-2.

12. Mohapatra P, Satapathy SR, Siddharth S, Das D, Nayak A, Kundu CN. Resveratro and curcumin synergistically induces apoptosis in cigarette smoke condensate transformed breast epithelial cells through a p21 Waf1/Cip1 mediated inhibition of Hh-Gli signaling. The international journal of biochemistry and cell biology. 2015;66:75-84.

13. Lai H-W, Chien S-Y, Kuo S-J, Tseng L-M, Lin H-Y, Chi C-W, et al. The Potential Utility of Curcumin in the Treatment of HER-2-Overexpressed Breast Cancer: An In vitro and In vivo Comparison Study with Herceptin. Evidence-Based Complementary and Alternative Medicine. 2012;2012:12.

14. Shao ZM, Shen ZZ, Liu CH, Sartippour MR, Go VL, Heber D, et al. Curcumin exerts multiple suppressive effects on human breast carcinoma cells. International Journal of Cancer. 2002;98(2):234-40.

15. Masuelli L, Benvenuto M, Fantini M, Marzocchella L, Sacchetti P, Di-Stefano $\mathrm{E}$, et al. Curcumin induces apoptosis in breast cancer cell lines and delays the growth of mammary tumors in neu transgenic mice. Journal of biological regulators and homeostatic agents. 2013;27(1):105-19.

16. Reddy S, Aggarwal BB. Curcumin is a non-competitive and selective inhibitor of phosphorylase kinase. FEBS letters. 1994;341(1):19-22.

17. Abdel-Latif GA, Al-Abd AM, Tadros MG, Al-Abbasi FA, Khalifa AE, Abdel-Naim AB. The chemomodulatory effects of resveratrol and didox on herceptin cytotoxicity in breast cancer cell lines. Scientific reports. 2015;5:12054.

18. Azios NG, Krishnamoorthy L, Harris M, Cubano LA, Cammer M, Dharmawardhane SF. Estrogen and resveratrol regulate Rac and Cdc42 signaling to the actin cytoskeleton of metastatic breast cancer cells. Neoplasia. 2007;9(2):147-58.

19. Yu R, Hebbar V, Kim DW, Mandlekar S, Pezzuto JM, Kong A-NT. Resveratrol inhibits phorbol ester and UV-induced activator protein 1 activation by interfering with mitogen-activated protein kinase pathways. Molecular Pharmacology. $2001 ; 60(1): 217-24$

20. Tabassum S, Zaki M, Afzal M, Arjmand F. Synthesis and characterization of Cu (II)-based anticancer chemotherapeutic agent targeting topoisomerase l $\alpha$ : In vitro DNA binding, pBR322 cleavage, molecular docking studies and cytotoxicity against human cancer cell lines. European journal of medicinal chemistry. 2014; 74:509-23

21. Francis DRL. Rapid colorimetric assay for cell growth and survival: modifications to the tetrazolium dye procedure giving improved sensitivity and reliability. $\mathrm{J}$ Immunol Methods. 1986;89(2):271-7.

22. Chou T-C. Theoretical basis, experimental design, and computerized simulation of synergism and antagonism in drug combination studies. Pharmacological reviews. 2006;58(3):621-81.

23. Alobaedi $\mathrm{OH}$, Talib WH, Basheti IA. Antitumor effect of thymoquinone combined with resveratrol on mice transplanted with breast cancer. Asian Pacific Journal of Tropical Medicine. 2017;10(4):400-8.

24. Walle T. Bioavailability of resveratrol. Annals of the New York Academy of Sciences $2011 ; 1215(1): 9-15$

25. Anand $P$, Kunnumakkara AB, Newman RA, Aggarwal BB. Bioavailability of curcumin: problems and promises. Molecular pharmaceutics. 2007;4(6): 807-18.

26. Shaikh J, Ankola D, Beniwal V, Singh D, Kumar MR. Nanoparticle encapsulation improves oral bioavailability of curcumin by at least 9-fold when compared to curcumin administered with piperine as absorption enhancer. European Journal of Pharmaceutical Sciences. 2009;37(3):223-30.

27. Yallapu MM, Jaggi M, Chauhan SC. Poly ( $\beta$-cyclodextrin)/Curcumin Self-Assembly: A Novel Approach to Improve Curcumin Delivery and its Therapeutic Efficacy in Prostate Cancer Cells. Macromolecular bioscience. 2010;10(10):1141-51.

28. Wang S, Su R, Nie S, Sun M, Zhang J, Wu D, et al. Application of nanotechnology in improving bioavailability and bioactivity of diet-derived phytochemicals. The Journal of nutritional biochemistry. 2014;25(4):363-76.

29. Sessa M, Tsao R, Liu R, Ferrari G, Donsì F. Evaluation of the stability and antioxidant activity of Nano encapsulated resveratrol during in vitro digestion. Journal of agricultural and food chemistry. 2011;59(23):12352-60

30. Pushpalatha R, Selvamuthukumar S, Kilimozhi D. Nanocarrier mediated combination drug delivery for chemotherapy-A review. Journal of Drug Delivery Science and Technology. 2017.

Article History: Submission Date : 17-06-2017 ; Revised Date : 21-08-2017; Acceptance Date : 07-09-2017.

Cite this article: Pushpalatha R, Selvamuthukumar S, Kilimozhi D. Comparative Insilico Docking Analysis of Curcumin and Resveratrol on Breast Cancer Proteins and their Synergistic Effect on MCF-7 Cell Line. J Young Pharm. 2017;9(4):480-5. 